\title{
Moving into the future with EHPM
}

\author{
Yasuhito Yuasa
}

Published online: 15 December 2007

(C) The Japanese Society for Hygiene 2007

We are pleased to announce that Springer Japan will become the publisher of Environmental Health and Preventive Medicine (EHPM) beginning in January 2008. The worldrenowned Springer publishes more than 1,000 scientific journals, and as they become our publisher, we will witness a number of improvements and innovations in our journal.

One of them is the introduction of Online First, which makes it possible to publish accepted articles in electronic form prior to the appearance of the printed journal, without having to wait for the completion of an entire issue, printed or electronic. This means a significant reduction in publication time. As each article becomes ready for Online First publication, it will be published on the Web with its own publication date. Each article will receive a permanent, unique international identification code, the digital object identifier (DOI), which is registered with the International DOI Foundation (http://www.doi.org). Contributions published Online First, but not yet available in print, may be cited by journal title and DOI only. The print version also includes the DOI and date of online publication.

Another innovation is an online manuscript submission, review, and tracking system for the journal that will go into effect in April 2008. This system, Editorial Manager, is used by more than 2,500 journals and helps authors to submit their manuscripts and editors to manage the peer review process. The system also enables authors to check the status of their articles online as they undergo review.

Articles in EHPM will be accessible in more than 5,000 institutions worldwide through SpringerLink and consortium contracts for electronic journals. Thus, your articles in EHPM can be viewed by thousands of scientists. Through Springer Online Journal Archives, you can have electronic access to all articles in EHPM beginning with the first volume in 1996.

As I stated in an editorial entitled "EHPM for a new era" in the September issue of 2006, we are eager for acceptance in the Medline/PubMed Index and the Science Citation Index ("impact factor"). Springer's global team will help us to apply for these listings by using their international know-how and information. They have successfully assisted many Japanese scientific journals achieve the desired results in acceptance by these indexes.

I am confident that you will enjoy the benefits described above, and much more as well, with the upcoming changes at EHPM. Both now and in the future, we look forward to receiving your submissions.

Yasuhito Yuasa, Editor-in-Chief

Y. Yuasa $(\bowtie)$

Department of Molecular Oncology,

Graduate School of Medicine and Dentistry,

Tokyo Medical and Dental University, Tokyo, Japan

e-mail: yuasa.monc@tmd.ac.jp 